Authors: Jan Burek, Rafał Flejszar

Title of article: „Symulacja komputerowa pozycjonowania osi narzędzia w obróbce pięcioosiowej” (“Simulation of positioning of the tool axis in five-axis machining")

Mechanik, Vol. 91, No. 8-9 (2018): pages 646-648

DOI: https://doi.org/10.17814/mechanik.2018.8-9.101

\title{
Simulation of positioning of the tool axis in five-axis machining
}

\author{
Symulacja komputerowa pozycjonowania osi narzędzia \\ w obróbce pięcioosiowej
}

\section{JAN BUREK \\ RAFAŁ FLEJSZAR *}

The work analyzed the impact of the positioning of the tool axis on the dynamics of the rotary axis of the machine in the five-axis processing of elements with complex geometry. A strategy for smooth change of positioning of the tool axis based on offset curves has been proposed, and verified using a NC code.

KEYWORDS: five-axis machining, CAM systems, complex surface machining

In the engineering industry, five-axis machining centers are increasingly being used to make any complex surface. An important stage in the production process of elements with complex geometry is the programming of tool paths, supported by CAM systems. The most commonly used technology for machining this type of part is to shape the surface with a ball cutter. This method allows to make any type of surface [1, 3].

One of the most important factors in the process of fiveaxis milling with a ball cutter is the positioning of the tool axis (fig. 1). This is done by the movements of controlled rotary axes of the machine tool (lead angle $\alpha$, tilt angle $\beta$ ). The weight of individual structural elements of the machine supports results in inertia forces, which is the reason for limiting the speed of changes in the angle of leading and tilting the tool $[2,4,5]$.

There are many technological variants used both for generating tool paths and for positioning tool axes. In the CAM system, the orientation of the tool axis can be defined relative to the workpiece or a specific point in the space or a specific curve [6].

The choice of the axis positioning method at the programming stage not only has purely theoretical consequences, but also affects the dynamics of the machine tool. In the case of elements with complex geometry, changes in the geometrical structure of the surface and deviations of shape are often observed, due to too high speed of changing the position of individual axes. The problem is usually solved by reducing the feed, however, it is possible to correct the positioning of the axis of the tool

* Dr hab. inż. Jan Burek prof. PRz (jburek@prz.edu.pl), mgr inż. Rafał Flejszar (r.flejszar@prz.edu.pl) - Katedra Technik Wytwarzania i Automatyzacji, Wydział Budowy Maszyn i Lotnictwa Politechniki Rzeszowskiej depending on the curve. Its shape is very important for the course of the machining process (fig. 2) [2, 5].

It often happens that the occurrence of a surface shape deviation is noticed until the machining stage. However, it is possible to verify and correct the positioning dynamics already during the design of the technological process, by introducing a smooth change in the lead angle $\alpha$ of the tool.

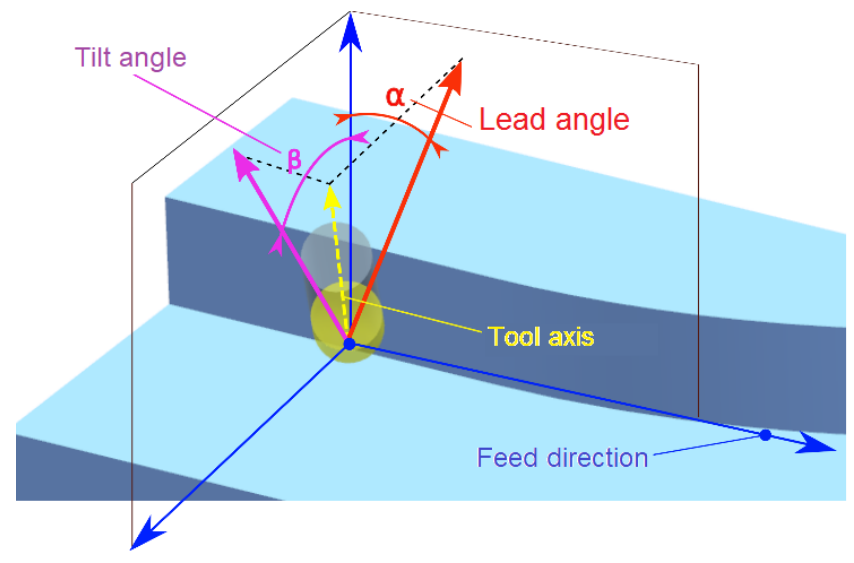

Fig. 1. Positioning of a ball cutter

a)

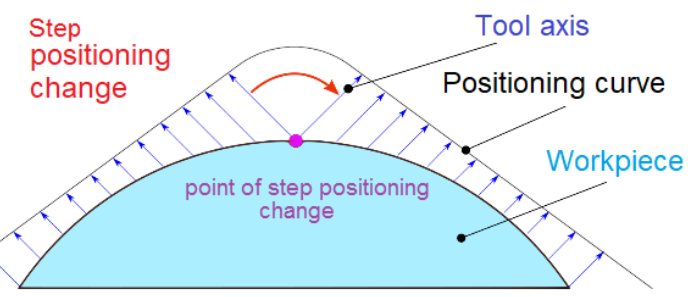

b) Smooth

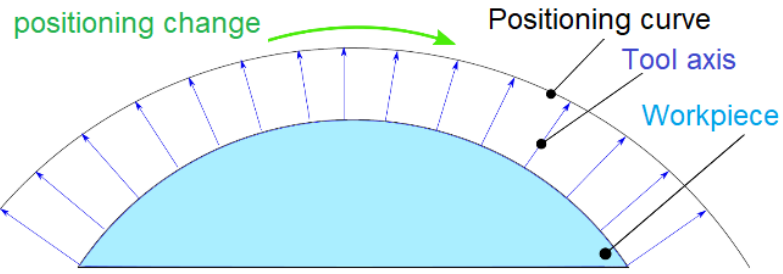

Fig. 2. Sequence of tool axis positioning: a) with step change, $b$ ) with smooth change 
The use of correction allows to reduce the maximum rotational speeds of the machine table axes. This in turn results in maintaining the dimensional accuracy of the workpiece without reducing the feed.

The aim of the work was to prepare and verify the strategy of smooth positioning of the tool axis in five-axis profile milling, with the highest possible stability of rotation speed of the rotary axis of the machining center table.

\section{Simulation tests}

The tests were carried out in the NX 11 system, on the test subject model (fig. 3). A model of this shape was chosen for the study, therefore there are convex and concave surfaces with different radius values on it.

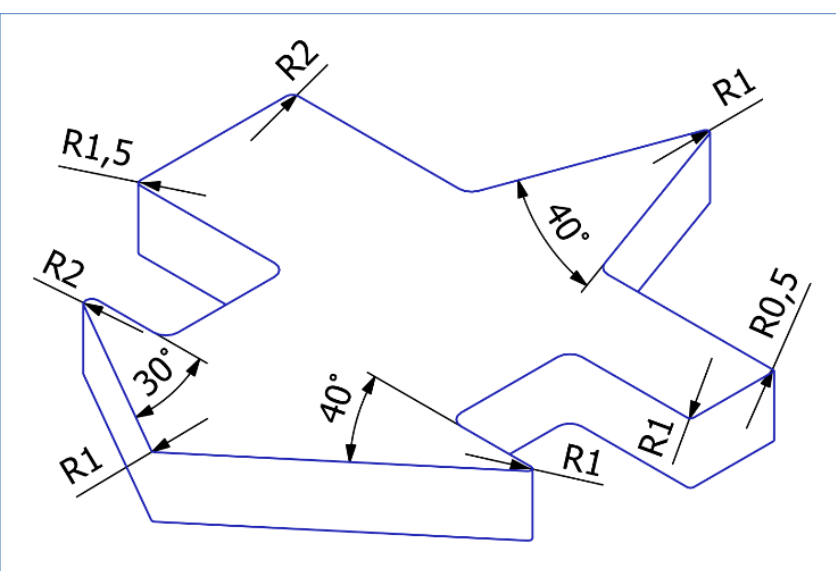

Fig. 3. Test model

The problem of a step change in the positioning of the tool axis appears mainly at relatively small values of the radii of the rounding, therefore it is assumed that the concave corners are dimensionally compatible with the radius of the cutting tool.

The research consisted of simulation of profile milling with a ball cutter with a diameter of $\varnothing 8 \mathrm{~mm}$. The following technological parameters were adopted: tilt angle $\beta=20^{\circ}$ and feedrate $v_{\mathrm{f}}=2400 \mathrm{~mm} / \mathrm{min}$.

A milling machining program has been programmed into the machining center with the $A$ and $C$ axes in the table (rotary-swivel table). The change in the position of the $C$ axis of the rotary table was investigated depending on the positioning strategy.

Two strategies for driving the axis have been selected:

- Away from part (fig. 4a) - a strategy in which the tilt angle $\beta$ of the tool axis has a constant value in relation to the workpiece, and the lead angle $\alpha$ of the tool axis has a constant value equal to 0 ,

- Toward line (fig. 4b) - a strategy in which the lead angle of the tool axis $\alpha$ is determined by the normal planes to the defined curve, and the tilt angle $\beta$ of the tool axis, considered in the plane normal to the given curve, has a constant value.

The positioning curves were based on the offset curve from the contour of the test model (fig. 5a). The distances of centers of convex and concave roundings were modified with the assumption that the newly created rounding is tangent to the original offset curve. The offset of rounding centers was made in a symmetrical direction to the two neighboring faces of the model. In the case of convex roundings, the center of the new fillet was located in the distance $C X$ from the center of the rounding of the convex workpiece (fig. $5 b$ ). In the case of concave roundings, the distance to the center of the radius of the rounding of the concave workpiece was offset by the distance OFFSET + CV (fig. $5 c$ ).
The geometry of the test model constituted limitations for the parameters OFFSET, CX and CV (see table).

TABLE. Model constraints
\begin{tabular}{|l|c|}
\hline OFFSET, mm & $\leq 10$ \\
\hline$C X, \mathrm{~mm}$ & $\leq 8$ \\
\hline$C V, \mathrm{~mm}$ & $\leq 12$ \\
\hline$C X+C V, \mathrm{~mm}$ & $\leq 14$ \\
\hline
\end{tabular}

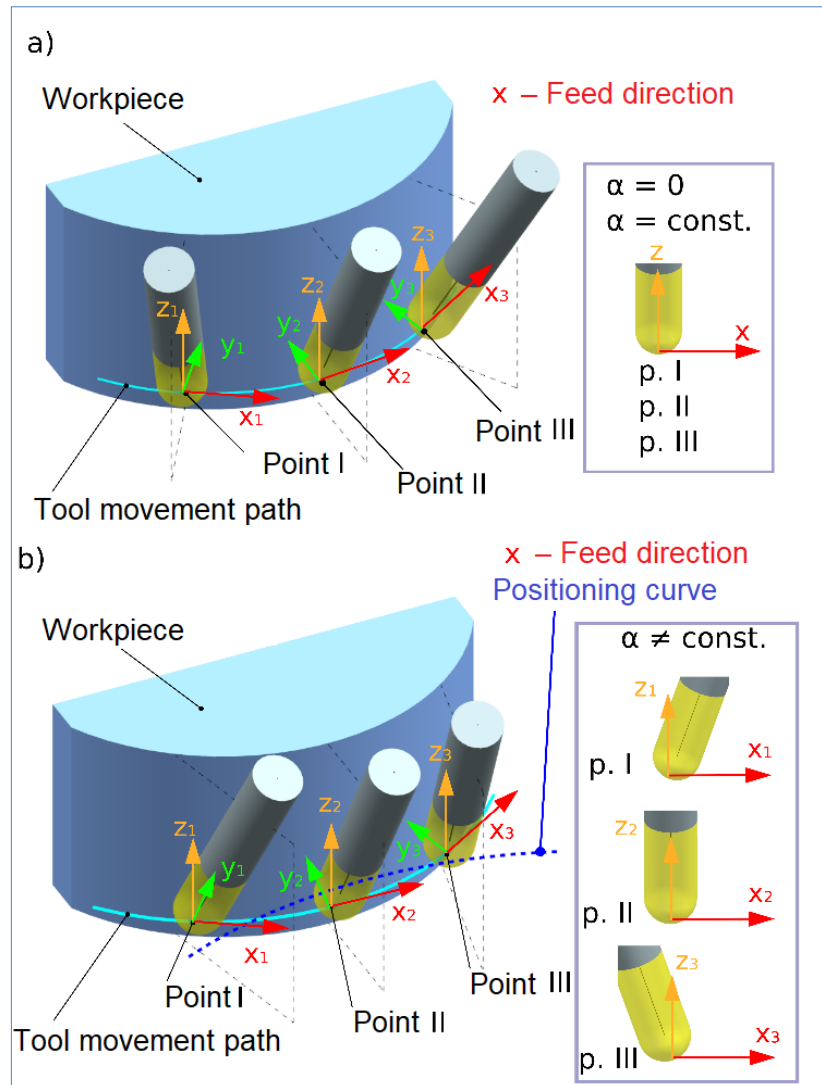

Fig. 4. Strategies for guiding the tool axis: a) away from part, b) toward line

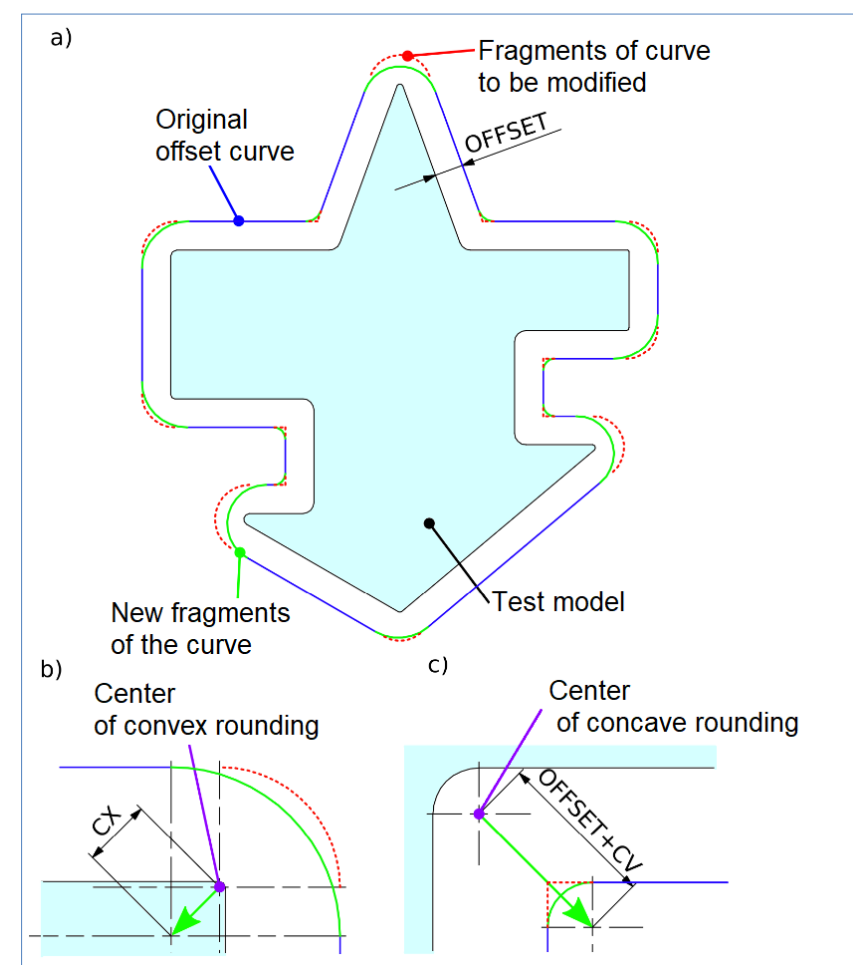

Fig. 5. Offset curve: a) general view, b) dimensioning of convex roundings, $c$ ) dimensioning of concave roundings 


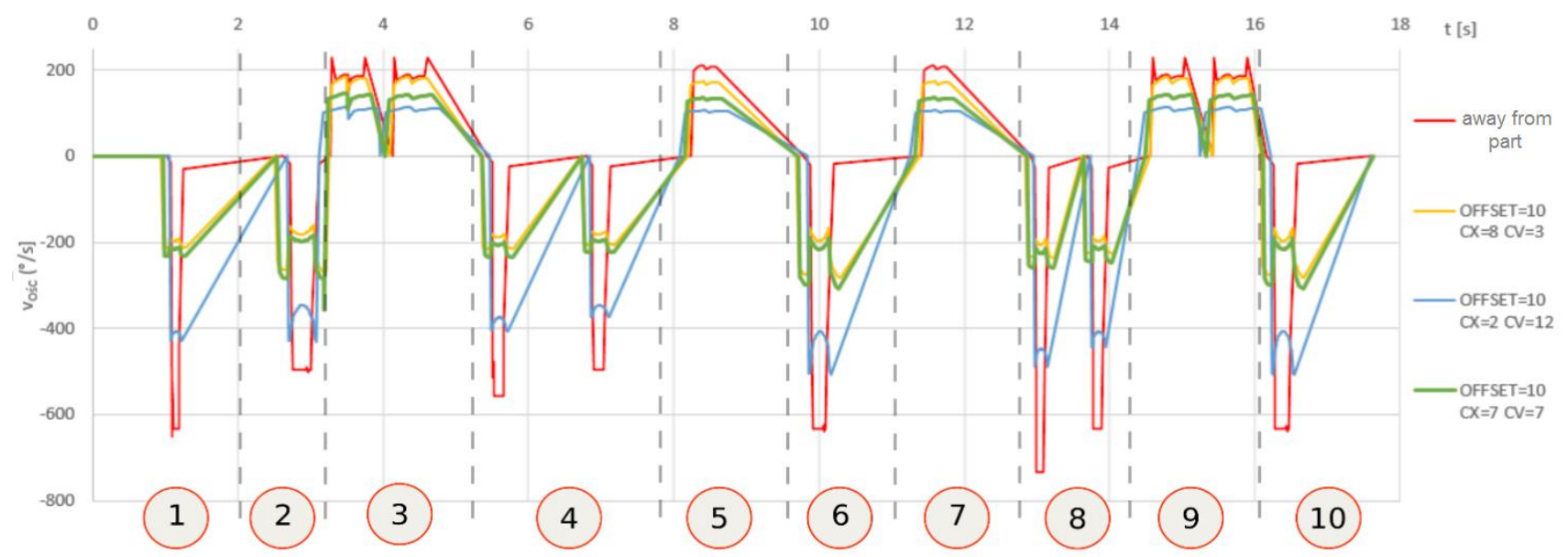

Fig. 7. Graph of rotational axis speed changes for different axis positioning strategies depending on the machining time

These limitations resulted from the assumed requirement of continuity G1 of the offset curve, the angles between adjacent walls, the radii of rounding concave corners, and the minimum offset below which the tool paths are generated incorrectly.

Simulations were made to change the position of the $C$ axis for individual positioning methods, using different combinations of OFFSET, CX and CV parameters.

\section{Analysis of results}

In order to analyze the results, areas characterized by concave or convex roundings were isolated (fig. 6). On the basis of the generated NC code, graphs of changes in the position of the rotary axis $\mathrm{C}$ were made depending on the time (fig. 7). The characteristic areas have been marked on them.

As a reference strategy, the machining with positioning away from the part was assumed, in the case of which the step change in speed of the rotary axis turned out to be very high - in the order of $700 \%$ s. It is also visible that positioning at convex corners is a much bigger problem compared to positioning at concave corners (the step change in speed is over $200 \%$ higher). It can be assumed that shape errors would occur after the machining program was implemented, especially on convex round corners.

As the value of the $C X$ parameter increases (increasing the convex roundness), the angular velocity of the $C$ axis drops. After using the parameter $C X=8 \mathrm{~mm}$ in area 8 , the value of the tested value is almost threefold.

With the increase in the $\mathrm{CV}$ parameter (increasing the concave rounding), a decrease in the angular velocity of the $C$ axis can also be observed. It is smaller than in the case of convex rounding, however, after using the parameter $\mathrm{CV}=12$ $\mathrm{mm}$, an almost two-fold decrease in the tested value was observed.

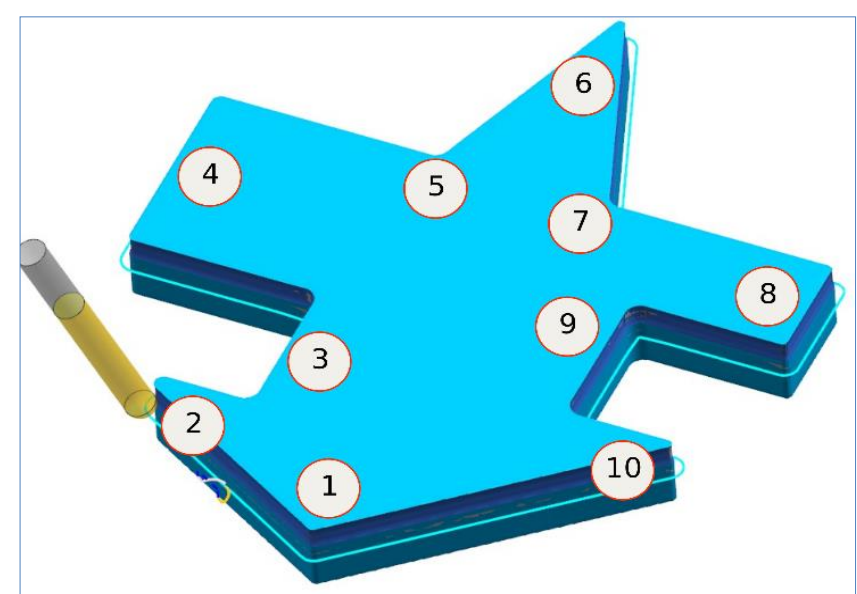

The OFFSET parameter did not significantly affect the test results, however, its selection limited the possibility of entering the remaining parameters: too high value of this parameter was limited by the CV parameter, and too small caused limitations of the $C X$ parameter.

Model constraints made it impossible to choose any positioning parameters, which is why various parameter combinations were verified. The best results were obtained for a symmetrical distribution of $C X=C V=7 \mathrm{~mm}$

\section{Conclusions}

Modern CAM systems make it possible to predict the operation of a machining program on a real machine tool at the design stage of the machining process. This allows you to potentially shorten the time of implementation and retooling and increase the stability of the machine.

Based on the results of the research, it can be concluded that the strategy of positioning the tool axis in five-axis machining has a significant impact on the dynamics of the machining process.

Depending on the positioning method, it is possible to achieve much lower speeds of rotary axes, which can have a significant impact on the quality of the elements being made. Changing the positioning method allows you to increase the feed rate, which was initially reduced due to geometrical errors.

The proposed positioning strategy has achieved its intended purpose. It was possible to reduce the $\mathrm{C}$ axis rotational speeds on convex roundings (up to approx. 60\%) and on concave roundings (up to approx. $25 \%$ ).

The problem of the optimal selection of parameters and the impact of the proposed strategy on the technological parameters of the process can be the subject of further research.

\section{REFERENCES}

1. Burek J., Żurek P., Żurawski K. „Wpływ kąta pochylenia na chropowatość powierzchni złożonych po obróbce frezem kulistym". Mechanik. 10 (2016): pp. 1478-1479.

2. Grandguillaume L., Lavernhe S., Tournier C. "A tool path patching strategy around singular point in 5-axis ball-end milling". International Journal of Production Research. 54, 24 (2016): pp. 7480-7490.

3. Lazoglu I., Manav C., Murtezaoglu Y. "Tool path optimization for free form surface machining". CIRP Annals - Manufacturing Technology. 58, 1 (2009): pp. 101-104.

4. Sadílek M., Čep R., Budak I., Soković M., Kowalski J. "Aspects of using tool axis inclination angle". Strojniski Vestnik. 57, 9 (2011): pp. 681-688.

5. Wang N., Tang K. "Automatic generation of gouge-free and angular-velocity-compliant five-axis toolpath". Computer-Aided Design. 39, 10 (2007): pp. 841-852.

6. Documentation of the NX 10 system. 
Translation of scientific articles, their computer composition and publishing them on the website www.mechanik.media.pl by original articles in Polish is a task financed from the funds of the Ministry of Science and Higher Education designated for dissemination of science.

Ministry of Science and Higher Education

Republic of Poland 